\title{
Necrotizing Fasciitis of the Breast: A rare presentation in post- partum mother
}

\author{
Maroti P.Pote ${ }^{1}$, Vidyadhar P.Kelkar ${ }^{2}$, Laxmikant Bhople ${ }^{3}$ 'Akshay Patil ${ }^{4}$ \\ 1,2,3,4 (Department of general surgery, Dr.Shankarrao Chavan government medical college, Nanded, India)
}

\begin{abstract}
Necrotizing Fasciitis (NF) is a rapidly spreading flesh eating disease of skin \& subcutaneous tissue. It can involve any part of the body mostly involving perineal region \& anterior abdomen wall but breast involvement is rare. Thus early diagnosis and proper surgical treatment can prevent significant morbidity.
\end{abstract}

Keywords: Breast, Necrotizing Fasciitis, Postpartum period, Debridement

\section{Introduction}

Necrotizing Fasciitis is a potentially fatal condition usually polymicrobial in nature. It can occur after trauma, bites, around foreign body, surgical wound sites, IV drug abusers, in diabetes, immunocompromised host or can be idiopathic.

Puerperal period breast infection includes mastitis, abscess and rarely necrotizing fasciitis. Neglected breast infections in early puerperal period can land up in necrotizing Fasciitis. Delayed diagnosis and incomplete treatment can lead to increase sepsis and MODS (Multiple Organ Dysfunction Syndrome). Here we are presenting a case of Necrotizing Fasciitis of breast in early post-partum period.

\section{Case Report}

A 22 year Female patient P1 L1 Delivered by LSCS at rural hospital 15 years back came to casualty with complaints of blackish discoloration and purulent discharge from right breast since five days. She also complains of fever with throbbing pain in right breast. She has taken treatment for the same at private hospital in form of conservative management with no relief and further worsening of symptoms. Patient was referred to GMC, Nanded for further management.

On Examination patient was conscious oriented. She was febrile with pulse rate of $96 / \mathrm{min}$ and blood pressure of 100/60 mm Hg. There was blackish discoloration of skin of right breast with scaring of nipple and areola.Surrounding skin was red, edematous and inflammed. Opposite breast was has completely normal.[Fig.1] Her investigations revealed. Hb-6.5 gm \%, total WBC count - 10000/mm $\mathrm{m}^{3}$, platelet count- $2.80 \mathrm{lakh} / \mathrm{mm}^{3}$, blood glucose level (R) $-98 \mathrm{mg} \%$, blood urea $-22 \mathrm{mg} \%$, sr.creatinine $-0.7 \mathrm{mg} \%$, sr.bilirubin $-0.6 \mathrm{mg} \%$, sr.sodium $-140 \mathrm{mEq} / \mathrm{lit}$, sr.potassium $-4.2 \mathrm{mEq} / \mathrm{lit}$

Patient was started broad spectrum IV antibiotics, diagnosis of NF of right breast made and patient shifted to emergency operation theater for surgical debridement under general anesthesia.

Intra operative findings suggestive of necrosed skin, subcutaneous tissue, fact, fascia, with foul smelling purulent discharge [Fig.2]. Through debridement was done. All necrotic tissue and slough was removed. Histopathological examination of specimen confirmed the diagnosis.

Post-operativepatient's condition improved. She was given 3 blood transfusions. Antibiotics were given according culture and sensitivity report. (Culture report showed positive growth of Klebsiella pneumoniea, coagulase positive staphylococcus aureus and was sensitive for ceftazidime+sulbactum and piperacillin sodium+tazobactum sodium).

Daily cleaning and dressing dressing was done till healthy red granulation tissue appeared in a period of three weeks[Fig.3], after that split thickness skin grafting (STSG) was done [1].[Fig.4]

Patient was followed for one month after discharge and complete acceptance of graft and healthy wound was noticed.[Fig.5]

\section{Discussion}

$\mathrm{NF}$ of breast is a rare entity. Shah et al. reported the first case of NF of the breast in the Englishlanguage literature[2] ; otherwise NF is most commonly involves scrotum (Fournier's gangrene), Meleneys ulcer (affecting anterior abdominal wall), extremities and perennial region[3].NF affects mostly immune compromised host, diabetes, chronic renal failure, peripheral vascular disease, and advanced age.

In developing countries like India, patient often present late and at advanced stage due to illiteracy \& low socio - economic status. Patients are often neglected and show up after failed treatment from local remedies and quacks. 
Diagnosis of NF is mainly based on clinical ground (severe pain dispropotiate to local finding along with systemic toxicity) but adjutants like LRINEC scoring system can lead to precision in diagnosis[4].Early diagnosis is not always possible, because signs such as erythema, tenderness, swelling, and fever accompany other inflammatory states of skin and subcutaneous tissue (e.g., cellulitis). Large haemorrhagic bullae, skin necrosis, sensory deficits \& crepitus are all late features [5], [6].

There are mainly two types of NF described. Type I-polymicrobial in nature and type II-monomicrobial in nature usually caused by group A Streptococcus (Streptococcus pyogenes) either alone or in association with Staphylococcus aureus[7].

Management includes immediate supportive treatment in form of broad spectrum antibiotics and extensive surgical debridement [1], [8],[9].

\section{Conclusion}

Though NF of breast is rare and fatal condition, but with help of broad spectrum antibiotics and aggressive surgical intervention we can save prevent significant morbidity, thus as in this case we managed to save her right breast.

\section{References}

[1] Saira Nizami,Kamran Mohiuddin,Mohsin-e-Azam,Hasnain Zafar, ,Muhammed Ashraf Memon, Necrotizing Fasciitis of the Breastcase report. The Breast Journal, Volume 12 Number 2, 2006 168-169

[2] Shah J, Sharma AK, O’Donoghue JM, Mearns B, Johri A, Thomas V. Necrotising fasciitis of the breast.Br J Plast Surg2001;54:6768

[3] Hasham S, Matteucci P, Stanley PR, Hart NB. Necrotizing fasciitis.BMJ 2005; 330:830-33.

[4] Sarani B, Strong M, Pascual J, Schwab CW: Necrotizing fasciitis: Current concept and review of the literature. J Am Coll Surg 009, 208(2):279-288

[5] Korhan Taviloglu and Hakan Yanar .Necrotizing fasciitis: strategies for diagnosis and management. World Journal of Emergency Surgery2007, 2:19. doi:10.1186/1749-7922-2-19.

[6] Elliot DC, Kufera JA, Myer RA. Necrotizing soft tissue infection: risk factors for mortality and strategies for management. Annals of Surgery 1996; 224: 672-83.

[7] Elliott D, Kufera JA, Myers RA: The microbiology of necrotizing soft tissue infectionAm J Surg 2000, 179(5):361-6.

[8] McHenry CR, Piotrowski JJ, Petrinic D, Malangoni MA. 1995. Determinants of mortality for necrotizing soft-tissue infections. Ann. Surg. 221:558-563; discussion563-565

[9] Gurpreet Singh, Sunil K Sinha, Shailesh Adhikary, K Srinivas Babu,Pallab Ray, Satish K Khanna et al. Necrotising infections of soft tissues -a clinical profile, European Journal of Surgery 2002;168(60):366-71.

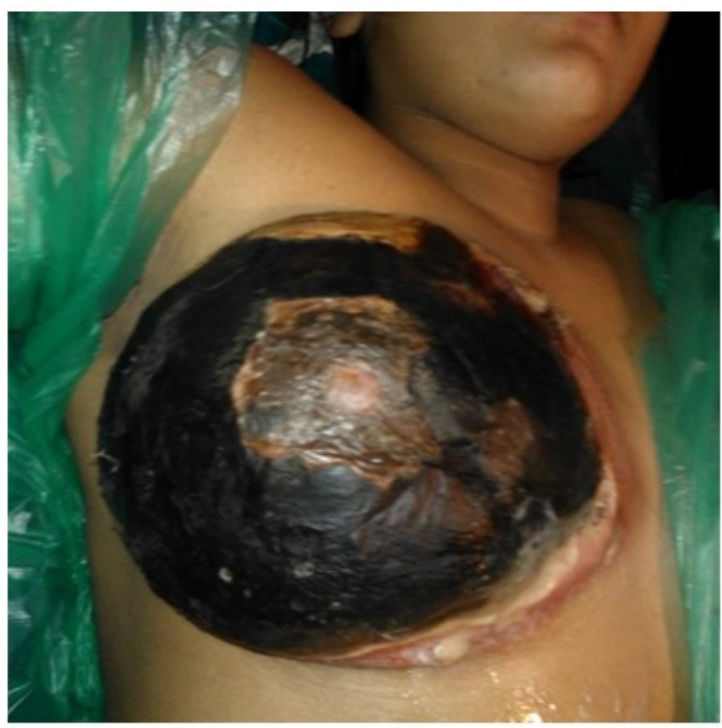

Fig.1 on admission

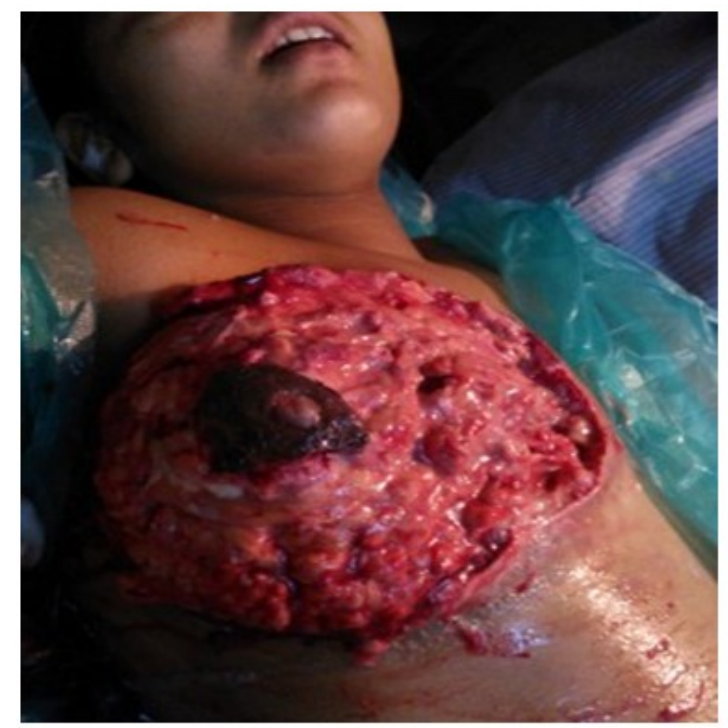

Fig.2 after debridement 


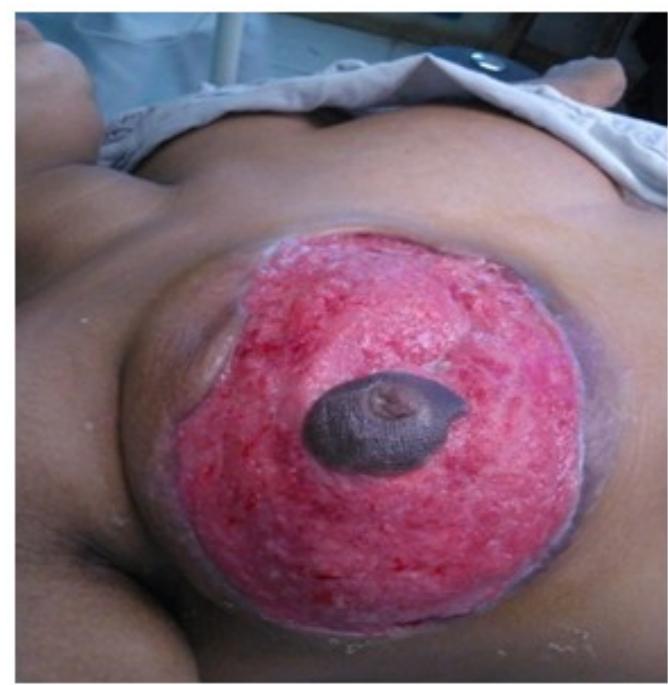

Fig.3 healthy granulation tissue

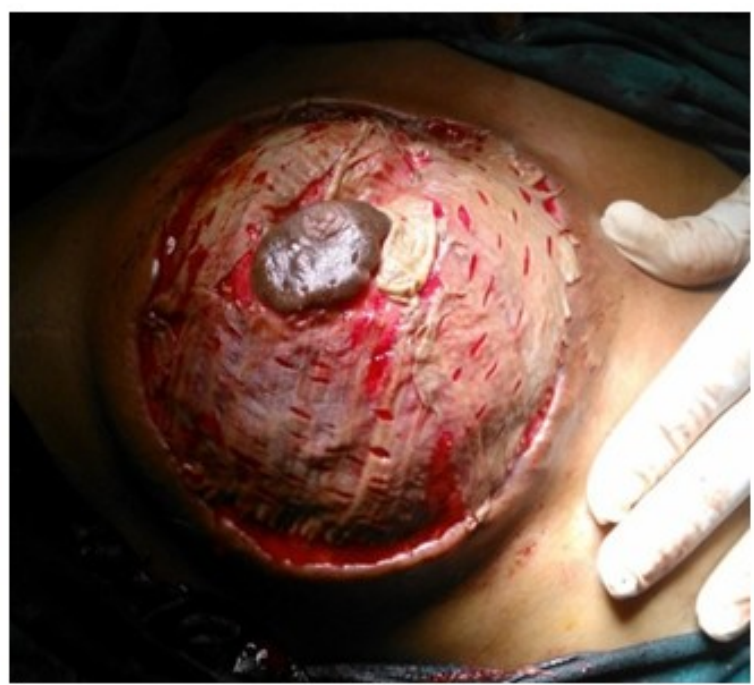

Fig.4 after skin grafting (STSG)

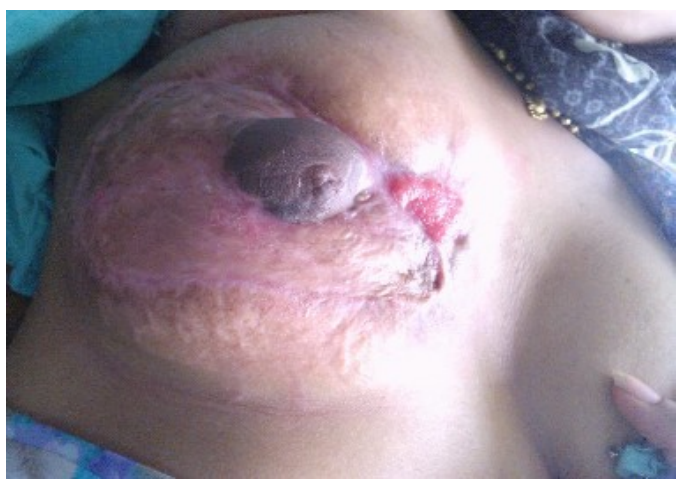

Fig.5 after 1 month follow up 